\title{
Role of Strategic Model and Spatial Analysis in the Decision-making process-Rural Karbala Governorate
}

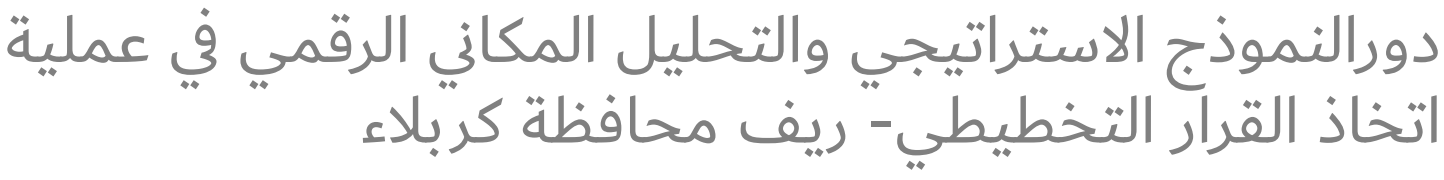

Ruqaya Abd AL Ridha Ghalii and Amna Hussain Sabree Ali ${ }^{2}$

رقية عبد الرضا غالي ' وآمنة حسين صبري عليr

${ }^{1}$ Ministry of Planning / Central Statistical Organization

${ }^{2}$ Urban Regional Planning Center for post graduation / Baghdad University

أوزارة التخطيط / الجهاز المركزي للاحصاء rمركز التخطيط الحضري الجطاز الاقليمي للدريط لاحماسات العليا / جامعة بغداد

\section{Abstract}

Received: 28 December 2017 Accepted: 2 February 2018

Published: 1 May 2018

Publishing services provided by Knowledge

(c) Ruqaya Abd AL Ridha Ghali and Amna Hussain Sabree Ali. This article is distributed under the terms of the Commons Attribution License, which permits unrestricted use and redistribution provided that the original author and source are credited.

Selection and Peer-review under the responsibility of the Urban Planning Iraq Conference Committee.
Digital spatial analysis of the Development Potentials in the rural areas of Karbala province using modern techniques as one of the planning methods. Enable the search to make a Planning Decision based on the planning indicators abstract from the analysis of Development Potentials and the Model of Strategic analysis and Spatial Interaction as A real indicators for the current and subsequent stages for Filtering the Development Alternative. And their potential to be better exploited to achieve the objectives set by choosing the model of Spatial Strategy based on Planning Decisions and future development J expand and exploit opportunities and minimize the impact of vulnerabilities and the use of force access points to balance efficiency and fairness in the distribution of the fruits of Development Which contribute to the future Spatial and rural Development.

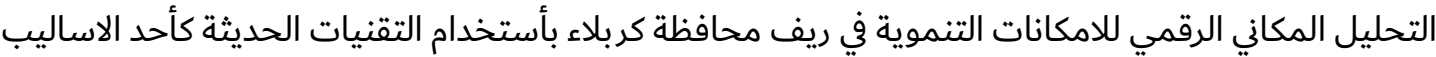

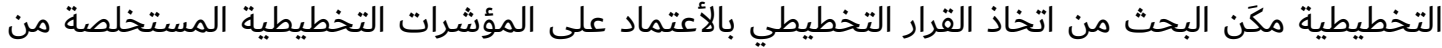

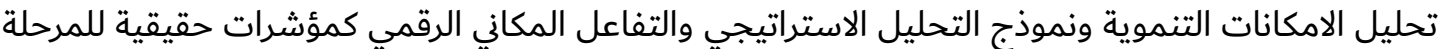

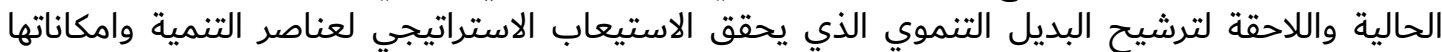

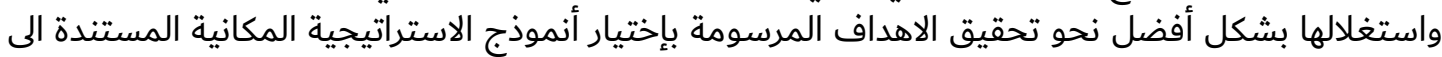

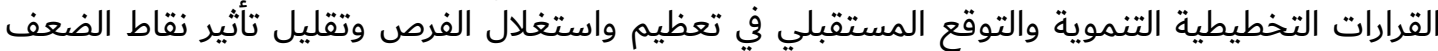

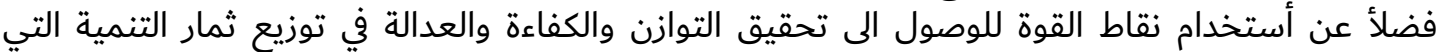
تساهم في تحقيق التنمية الريفية المكانية المستقبلية.

Keywords: Digital Spatial Analysis - Development Potentials-Strategic Model- Digital Spatial Interaction- Make a Planning Decision- Development Alternative- Planning Indicators - Modern Techniques GIS 
التحليل المكاني الرقمي - الامكانات التنموية - النموذج الاستراتيجي- التفاعل المكاني

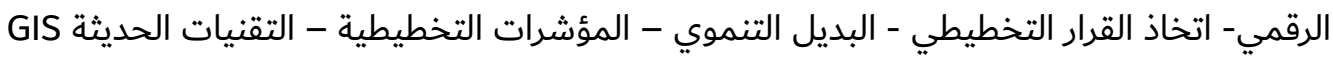

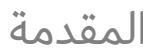

تحقيق التنمية المكانية الشاملة بالاعتماد على الأساليب والطرق والوسائل العلمية الحديثة يتطلَب أتخاذ

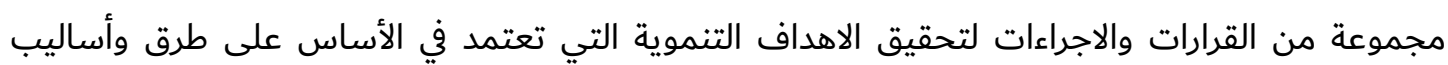
حديثة مرتبطة بالنمذجة والتحليل المكاني الرقمي لتحديد المؤشرات التخطيطية للتنمية المكانية من اجل الترات الترات

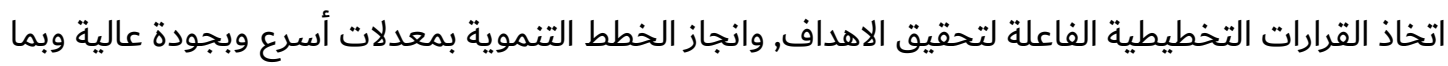
يقلل من الهدر في الموارد التنموية،والتفاوت المكاني عن طريق الاستخدام الافضل.

المشكلة

تكمن في عملية الربط بين النموذج الاستراتيجي والتفاعل والتحليل المكاني الرقمي بالاساليب الحديثة للامكانات التنموية للوصول الى المؤشرات التخطيطة التي تساعد في عملية اتخاذ القرار التخطيطي.

اتخاذ القرار التخطيطي اللازم لعملية التنمية الريفية من خلال الانموذج الاستراتيجي والتفاعل المكاني وتحليل الامكانات التنموية باستخدام اساليب تقنية المعلومات الحديثة.

\section{الفرضية}

مصفوفة التفاعل المكاني والانموذج الاستراتيجي والتحليل المكاني الرقمي بالاساليب الحديثة للامكانات التنموية لإتخاذ القرار التنموي المناسب لعملية التنمية الريفية.

\section{منهجية البحث}

أعتمد البحث على المنهج الوصفي التحليلي باستخدام التقنية المعلوماتية المكانية الحديثة لتحقيق الهدف

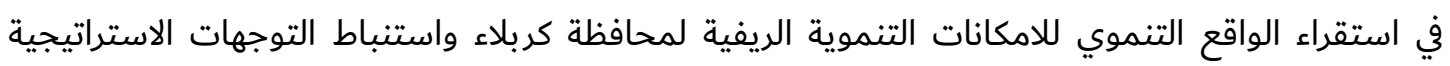
لبدائل التنمية المكانية الريفية.

المبحث الاول

النمذجة وعملية اتخاذ القرارات التخطيطية_الاطار المفاهيمي. 


\section{ا. النمذجة واتخاذ القرار التخطيطي الحديث}

في مجال التخطيط الحضري والاقليمي الانموذج يعني تبسيط لواقع الحال الحقيقي المعقد بأستخدام

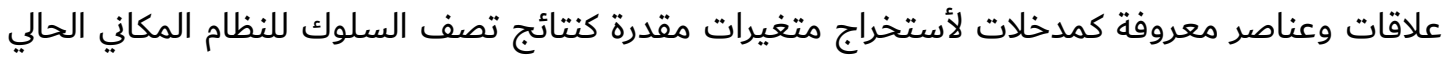
والمستقبلي. فالنموذج عبارة عن تمثيل جيد لمكونات المشكلة والعوامل المحيطة المؤثرة فيها, وان عملية

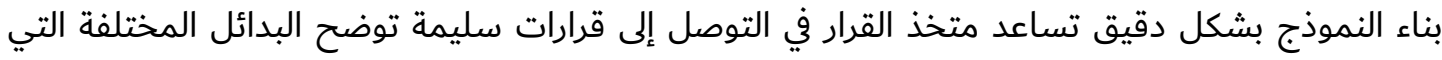
يتوصل البها النموذج حيث ان العملية التخطيطية تبدأ بتحديد مشكلة وتنتهي بإتباع إستراتيجية للكشف الكفاء

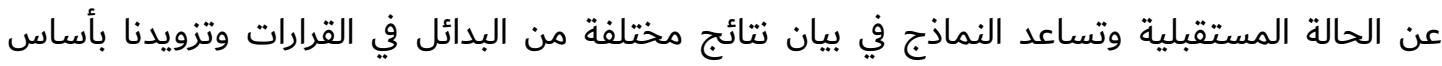

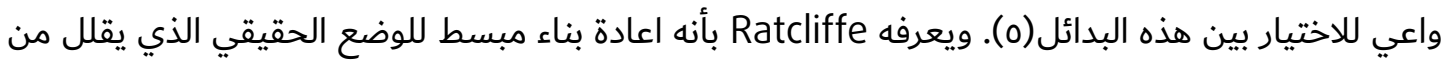

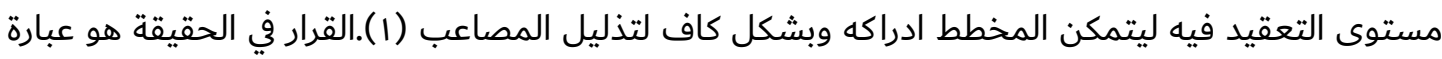

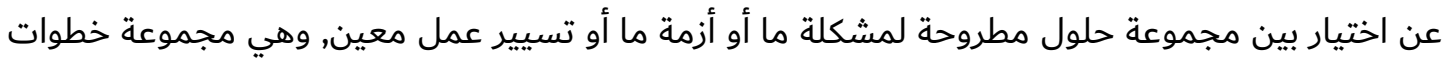
شاملة ومتسلسلة الهدف منها ايجاد الحل لمشكلة معينة او لتحقيق اهداف مرسومة اذ يعد القرار وحدة

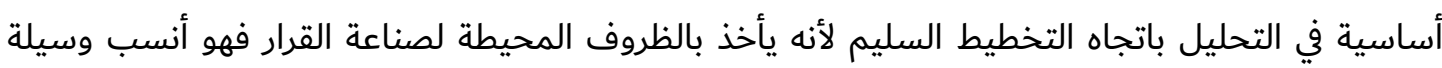

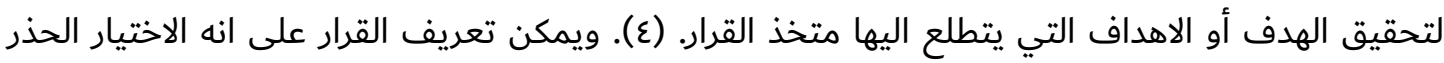

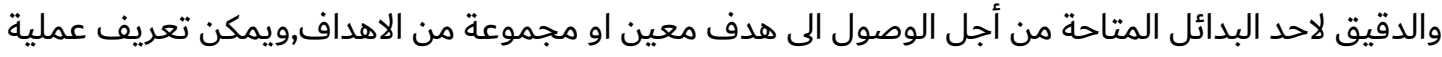
اتخاذ القرار على انها مجموعة خطوات شاملة ومتسلسلة الهدف منها ايجاد الحل لمشكلة معينة او لتحقيق

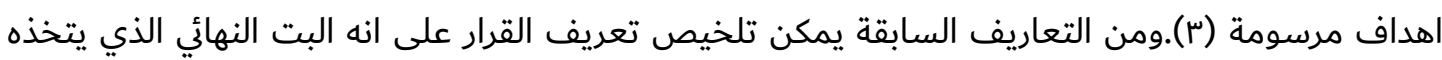

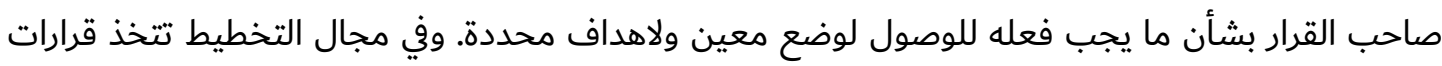

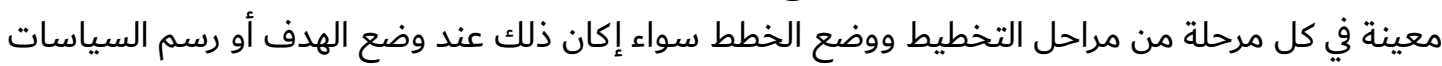

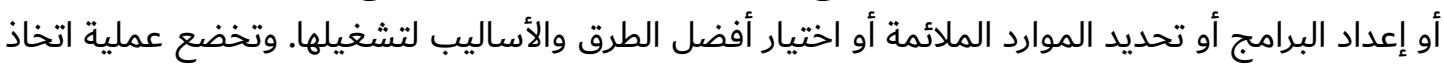

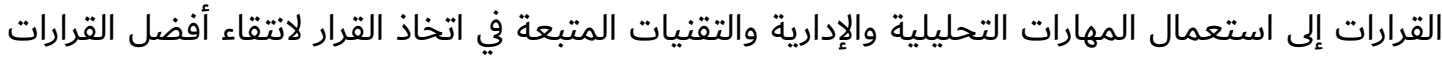

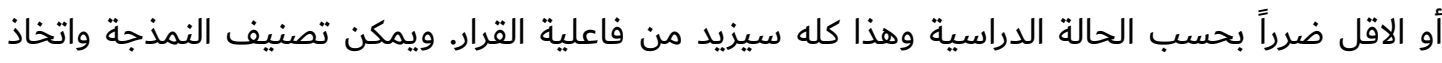
القرار الى تقليدية وحديثة، حيث ان تصنيف اساس المقارنة يكون بالاعتماد على مفهوم أستخدام النمذجة الحنة

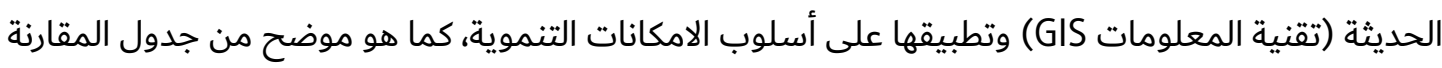

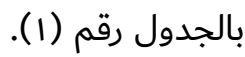
ويمكن أن نجمل فوائد, ووظائف نظم المعلومات الجغرافية وعلاقتها بالنمذجة ذات الصلة بالبحث في

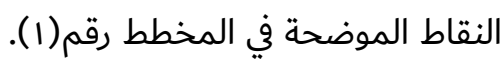

\section{r. القرارات التخطيطية الاستراتيجية}

القرار الاستراتيجي هو عملية اختيار بديل من بين بديلين أو أكثر لتحقيق هدف معين حيث إن القرارات

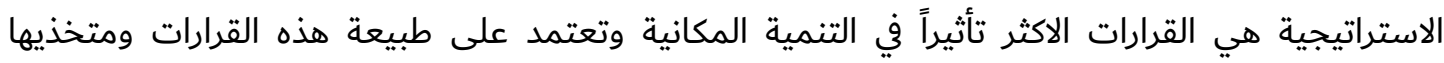

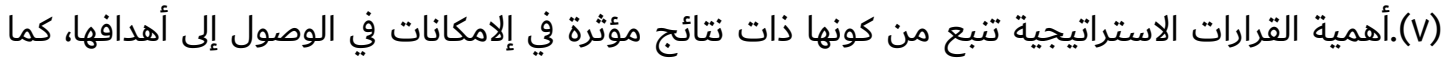

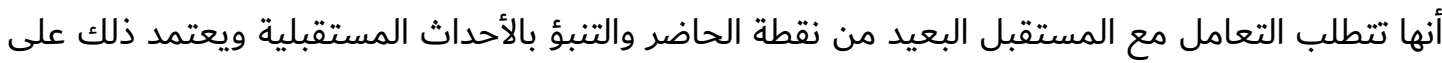

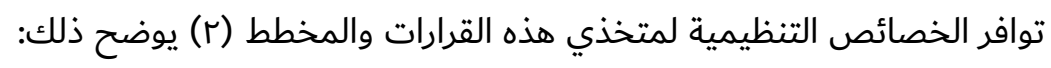




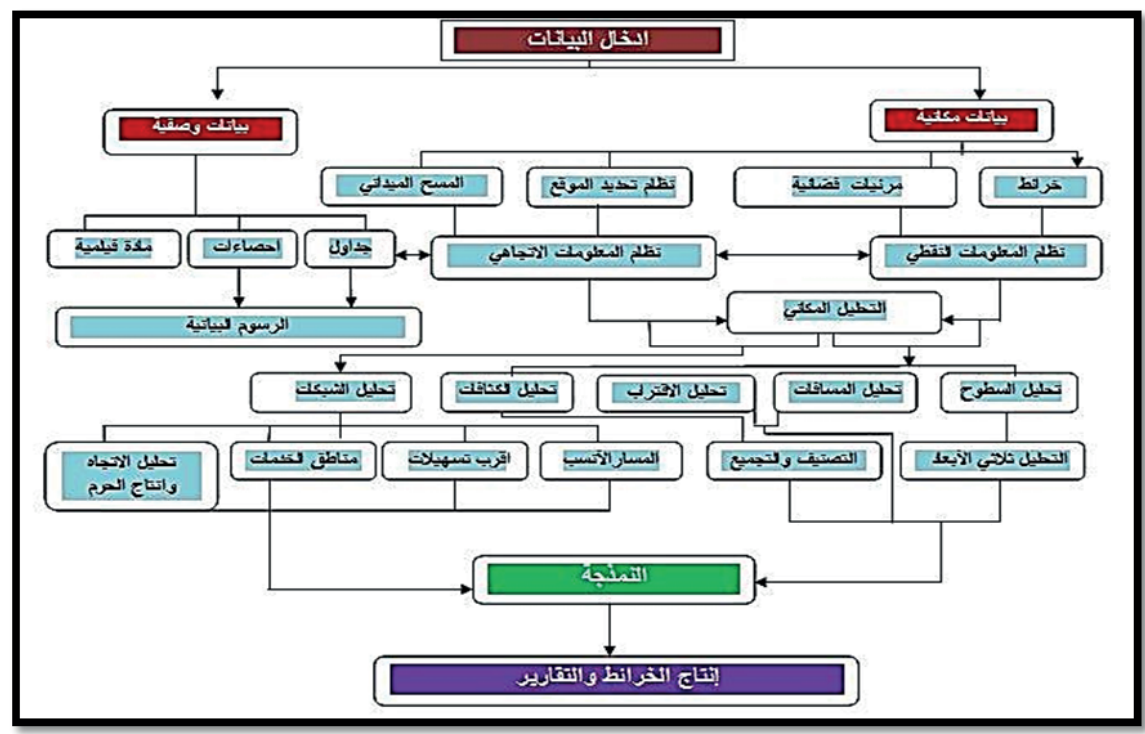

المخطط ا: وظائف نظم المعلومات الجغرافية. المصدر :الباحثة بالاعتماد على مصدر (r).

المبحث الثاني:تحليل إلامكانات التنموية الريفية لمحافظة كربلاء(الجانب العملي) ا - أسلوب الامكانات التنموية: آلية عمل أسلوب تحليل الأمكانات التنموية تعتمد على دراسة واقع حال منطقة الدراسة كما موضح في

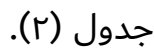

\section{والخارطة(r) تبين تحليل الامكانات التنموية (واقع الحال), والجدول (r) يوضح أوزان العوامل الرئيسية}

والفرعية.

\section{r- مصفوفة الامكانات التنموية لمحافظة كربلاء المقدسة:}

كالجدول (0) يوضح مصفوفة المؤشرات المستخلصة من تحليل الامكانات التنموية جدول (ع) لمحافظة

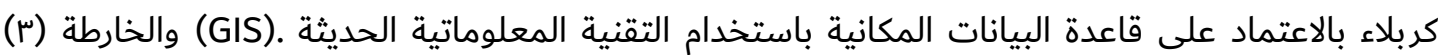
كذلك توضح الامكانات التنموية بموجب ذلك.

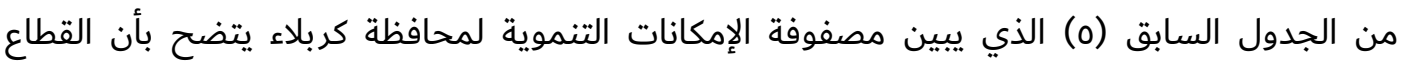

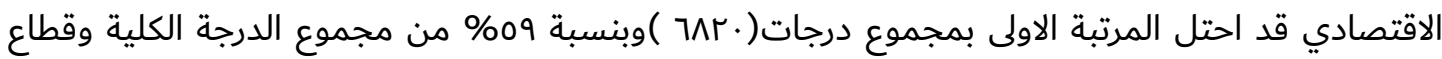

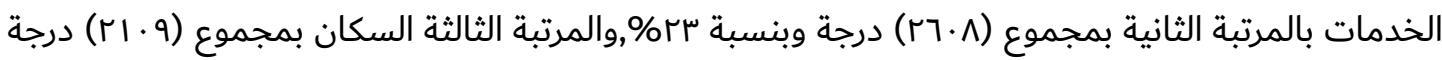

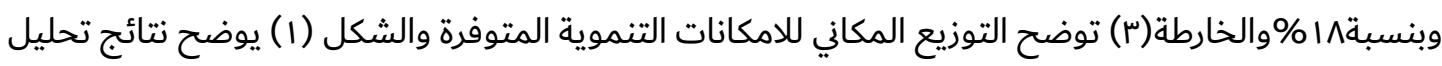

\section{بّ. التحليل الاستراتيجي وعملية تخاذ القرار}

من خلال ما توصلنا اليه من مؤشرات استطعنا الحصول عليها عن طريق تطبيق وتحليل الامكانات التنموية

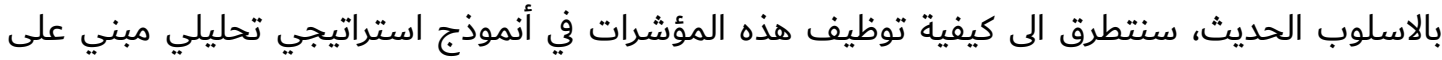

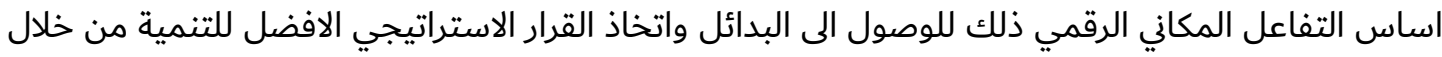

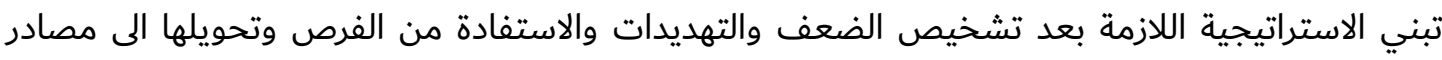


القوة من خلال مصفوفة التفاعل المكاني بين القطاعات والعوامل المؤثرة لاختيار البديل لتحقيق التنمية المكانية ثم تطوير المحافظة وهذا ماسعى إليه البحث من الوصول الى المؤشرات المكانية بالأسلوب الحديث التي توفر رؤية حقيقية للمرحلة الحالية واللاحقة لترشيح البديل التنموي الذي يحقق الاستيعاب الاستراتيجي

لعناصر التنمية ويؤمن استغلالها بشكل افضل نحو تحقيق الاهداف المرسومة. كما موضح بالمخطط (مال).

جدول ا: المقارنة بين النمذجة التقليدية والنمذجة الحديثة. المصدر: الباحثة

\begin{tabular}{|c|c|}
\hline النمذجة العايثة & النمذجة التقليدية \\
\hline 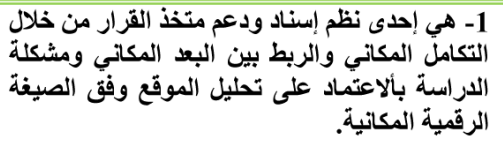 & 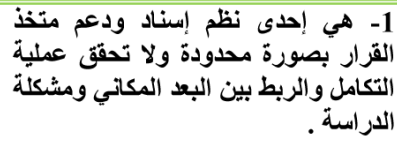 \\
\hline 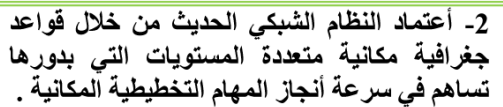 & 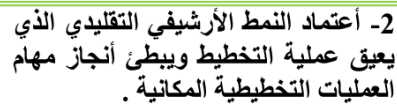 \\
\hline 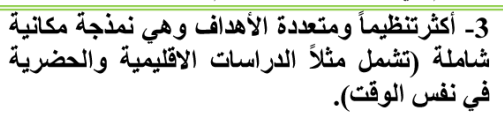 & 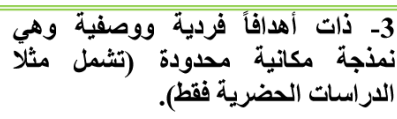 \\
\hline 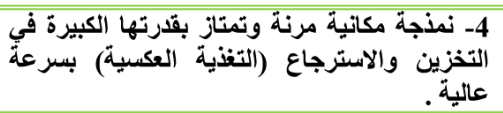 & 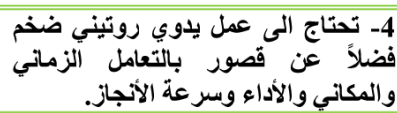 \\
\hline 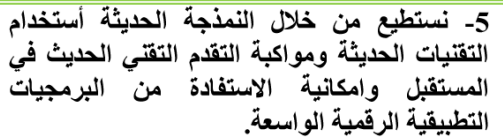 & 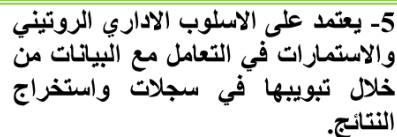 \\
\hline 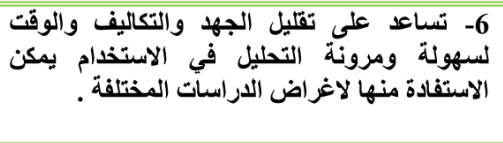 & 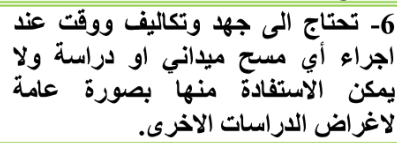 \\
\hline 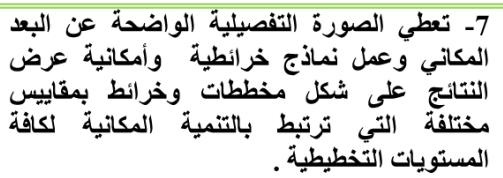 & ع - لا تعطي الصورة التفصيلية الواضحة \\
\hline 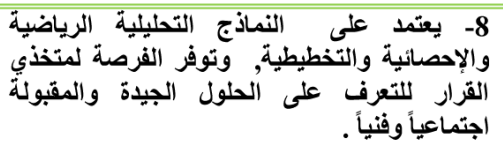 & 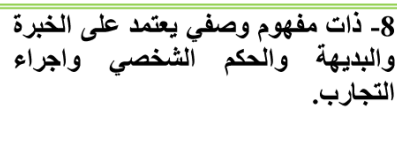 \\
\hline 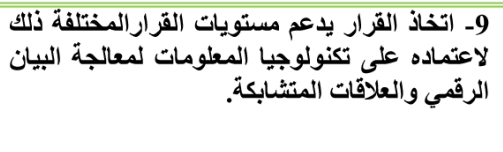 & 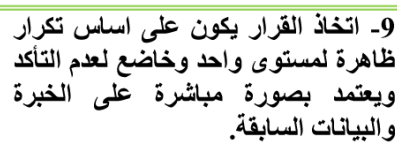 \\
\hline 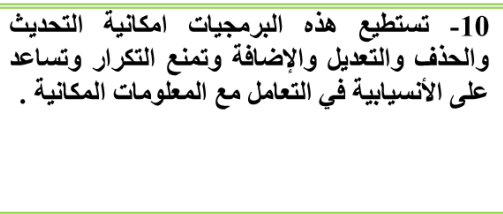 & 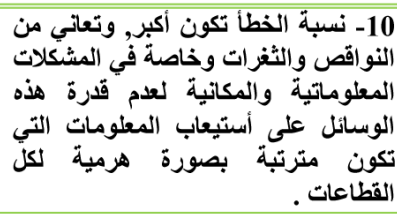 \\
\hline 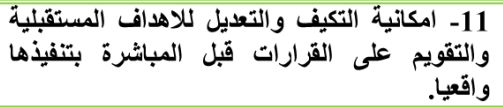 & 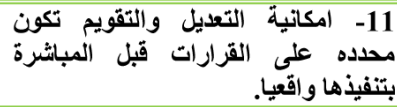 \\
\hline 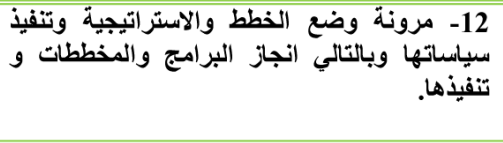 & 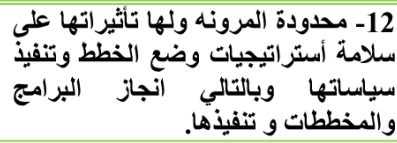 \\
\hline 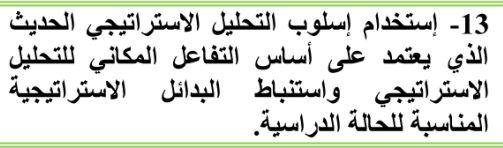 & 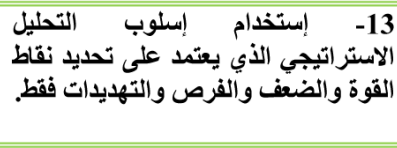 \\
\hline
\end{tabular}




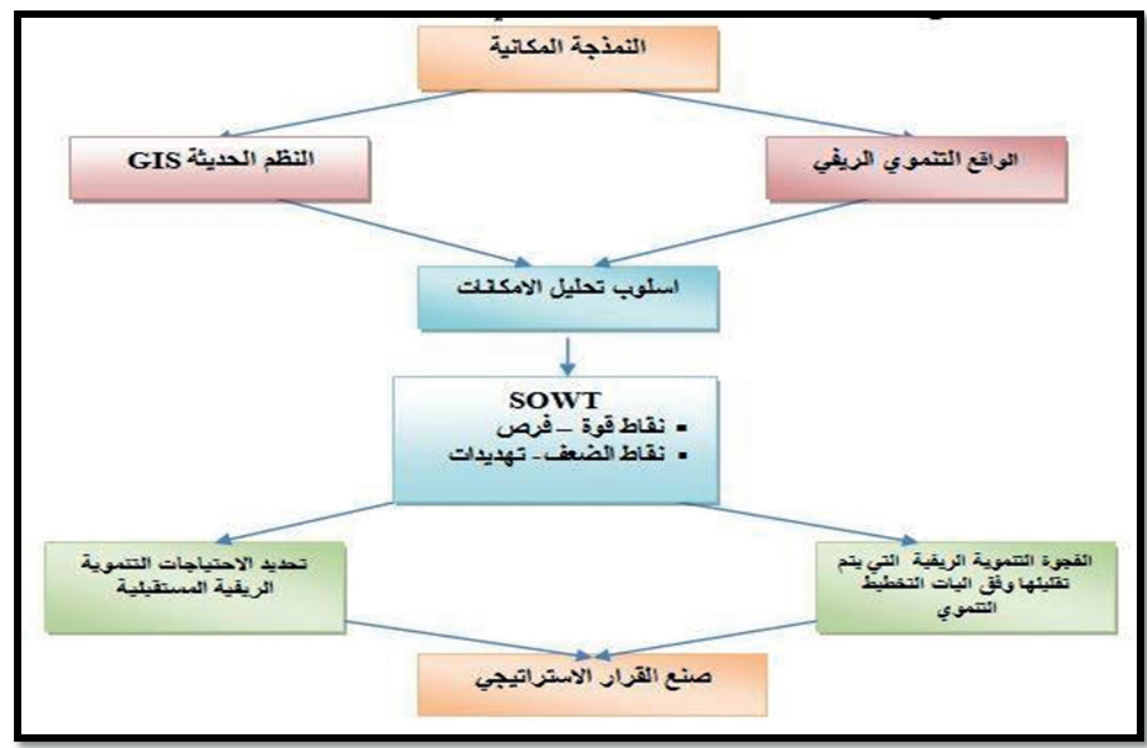

المخطط r: اهمية النمذجة المكانية في صنع القرارات الاستراتيجية للتنمية الريفية. المصدر: الباحثة

جدول r: بيانات واقع حال الريف محافظة كربلاء المقدسة.

\begin{tabular}{|c|c|c|c|}
\hline \multicolumn{3}{|c|}{ 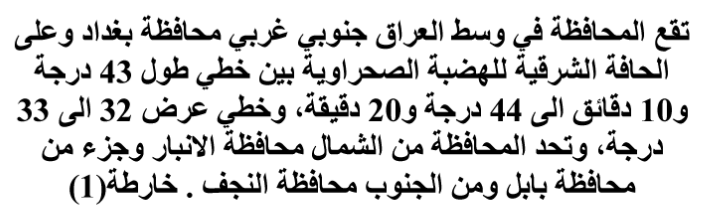 } & الموقع \\
\hline 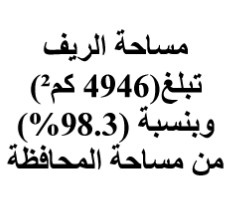 & مساحة الحضر تبلغة & 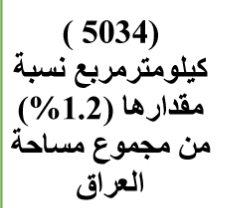 & المساحة \\
\hline عدد القرى (244) & 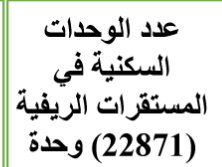 & عدد سكان الريفة & عدد السكان \\
\hline مساحة البساتين تقدر & |الزراعية المزروعية |لاراضة & المساحة الكلية & مساحة الار اضية \\
\hline
\end{tabular}




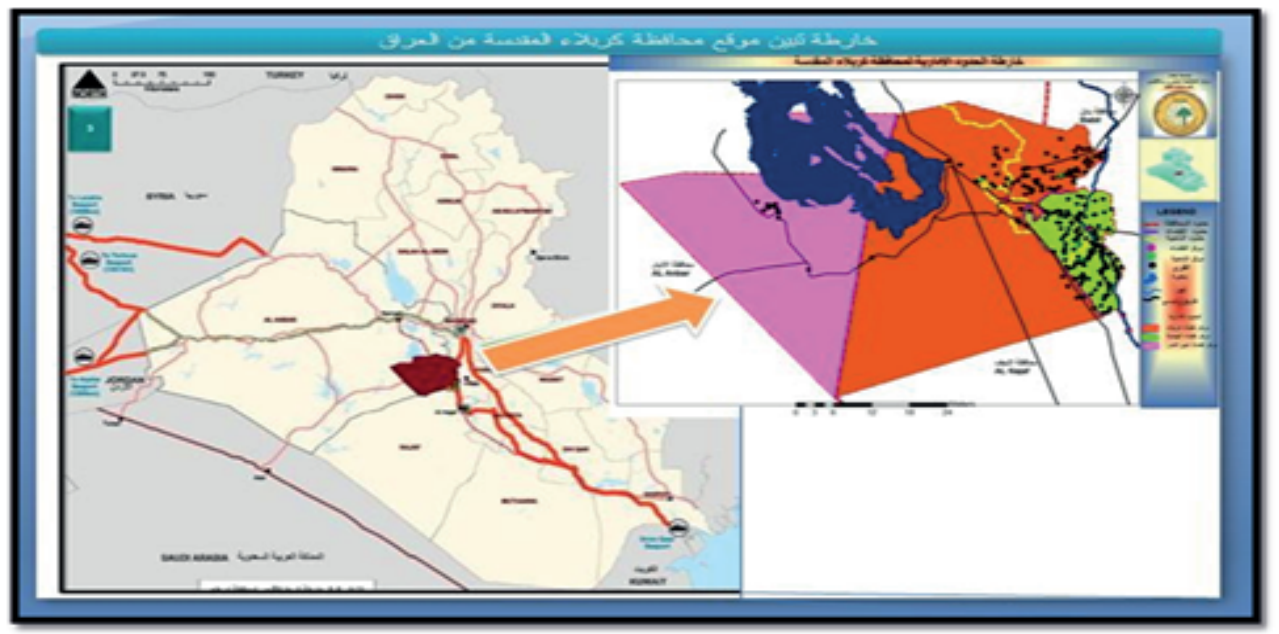

خارطة ا: موقع محافظة كربلاء المقدسة من العراق. المصدر : الباحثة بالاعتماد على مصدر (. 1).

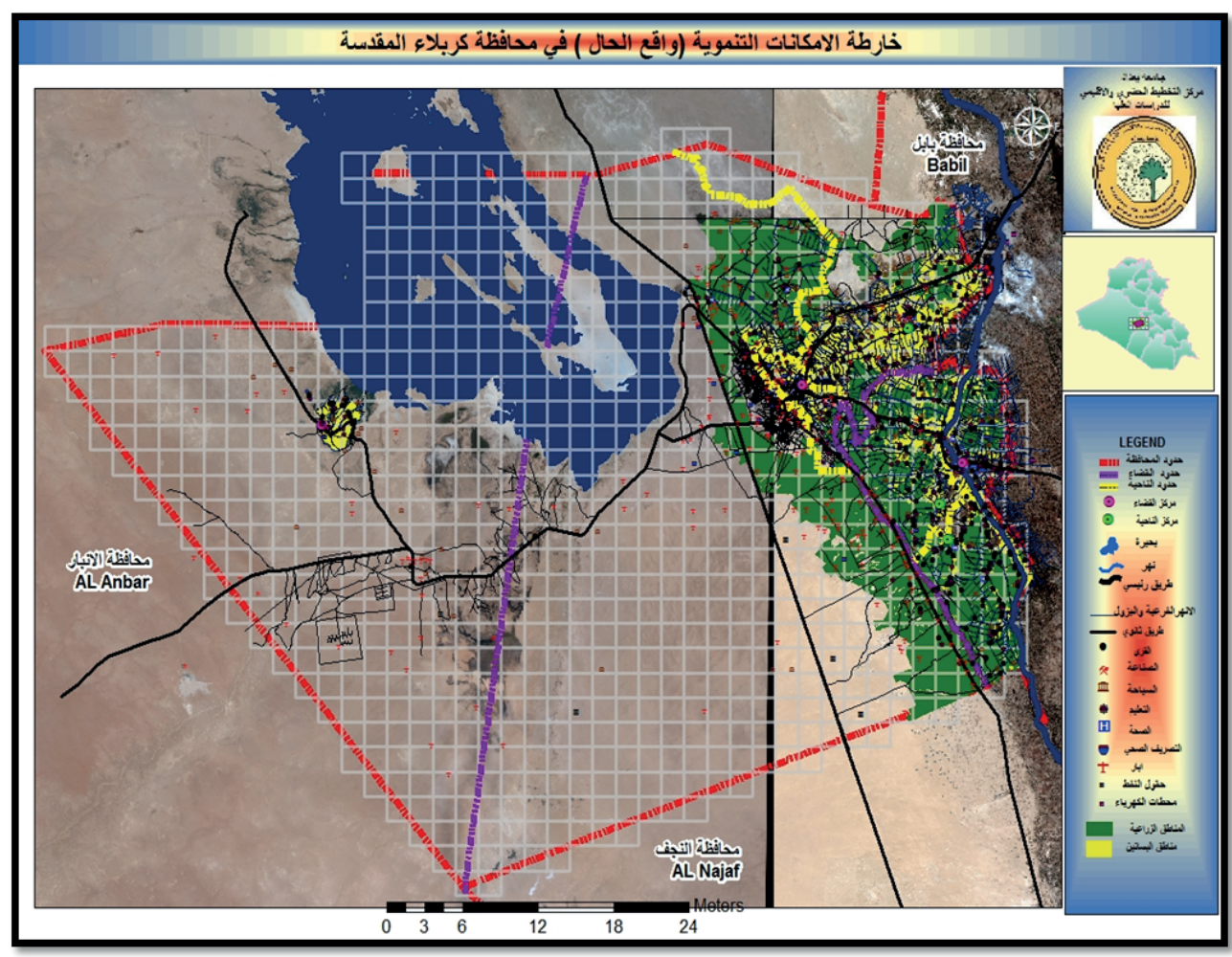

خارطة r: تحليل الامكانات التنموية (واقع الحال) لريف محافظة كربلاء المقدسة. المصدر: الباحثة 
جدول س: الاوزان للعوامل الرئيسية والفرعية. * الاراضي الزراعية المزروعة, والاراضي الزراعية غير المستغلة، والبساتين والنخيل لها

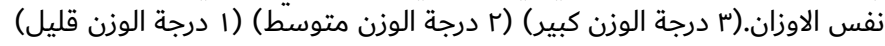

\begin{tabular}{|c|c|c|}
\hline 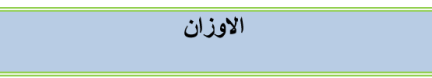 & العوامل الثانوية & الرئيسية \\
\hline \multirow{3}{*}{ 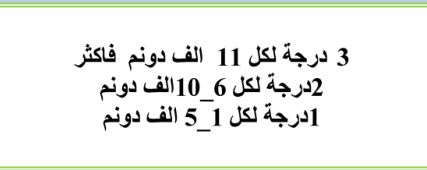 } & الاراضزي الززراعية & \multirow{11}{*}{ الاقتصاديل } \\
\hline & الازير المستخلة المية & \\
\hline & البساثين والنخيل & \\
\hline 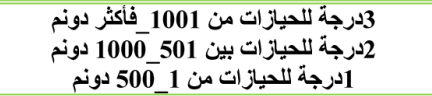 & الحيازات الززاعية & \\
\hline 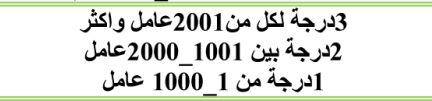 & الايدي العاملة & \\
\hline 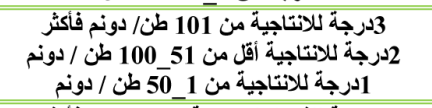 & الانتاجية الزراعية & \\
\hline 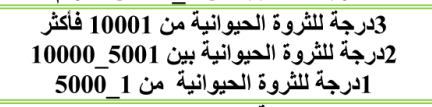 & الكفاءةالانتاجية & \\
\hline 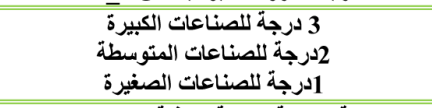 & الصناعات & \\
\hline 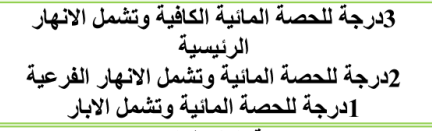 & الموارد المائية & \\
\hline 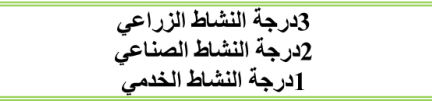 & الرئيسي النسكان & \\
\hline 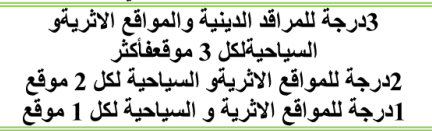 & الاثرية والدينية & \\
\hline الاوزان & العوامل الثانوية & المئيسية \\
\hline 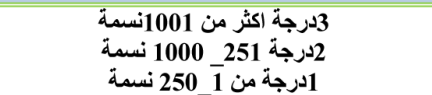 & عدد السكان & \multirow[t]{4}{*}{ السكان } \\
\hline 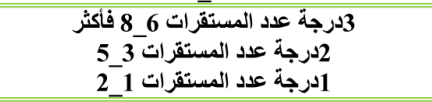 & علد المستقرات & \\
\hline 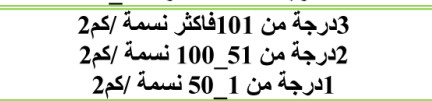 & الكثافة السكانية & \\
\hline 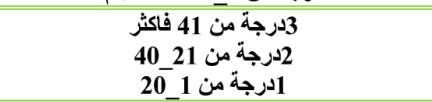 & الكثافة السكنية & \\
\hline 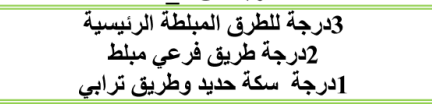 & الطرة & \multirow{6}{*}{ الخدمات } \\
\hline 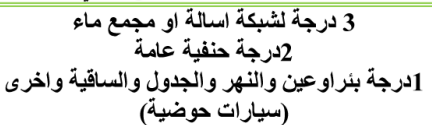 & 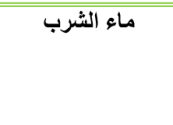 & \\
\hline 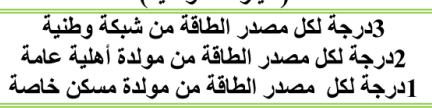 & الكهرباء & \\
\hline 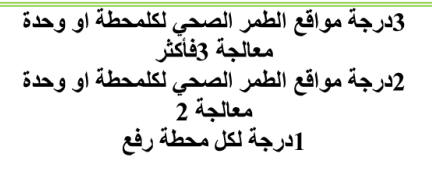 & الصرف الصحي & \\
\hline 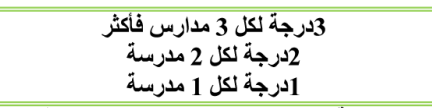 & 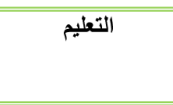 & \\
\hline 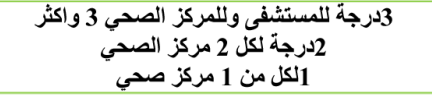 & الصحة & \\
\hline
\end{tabular}


جدول ع: تحليل الامكانات التنموية لمحافظة كربلاء المقدسة.

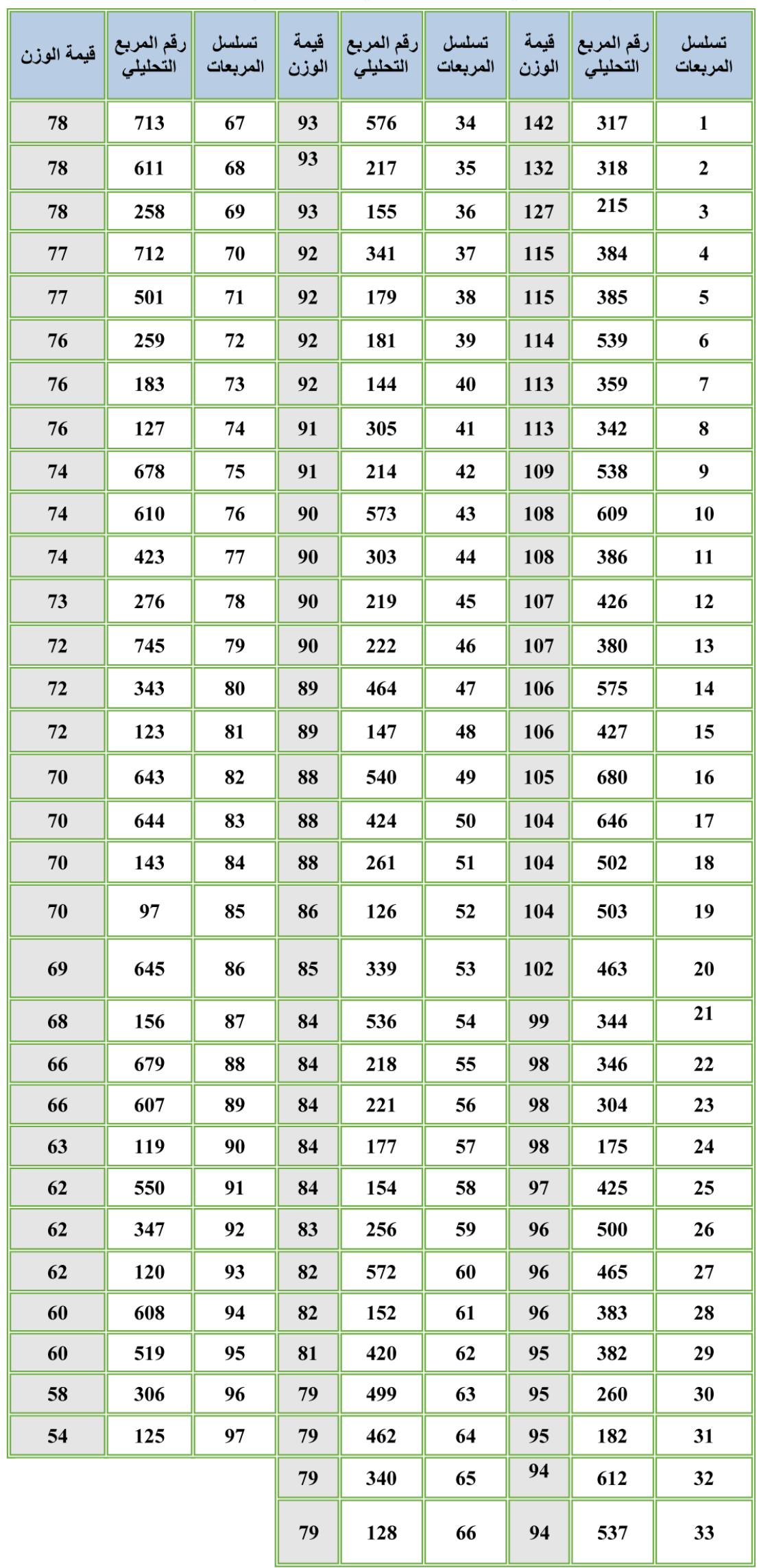


جدول 0: مصفوفة الإمكانات التنموية لمحافظة كربلاء المقدسة.

\begin{tabular}{|c|c|c|c|}
\hline الترجيحي & قالوزنة & الموُشرات & الرئيسية \\
\hline \multirow{14}{*}{6848} & 173 & 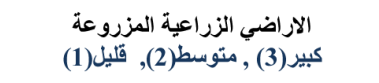 & \multirow{10}{*}{ الاقتصادي } \\
\hline & 251 & كبير(3), متوسطظية الفير مقليل (1) & \\
\hline & 139 & كبير(3) , متوسطاتين والنخيل قليل (1) & \\
\hline & 42 & 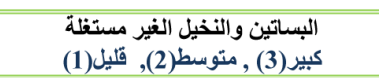 & \\
\hline & 100 & 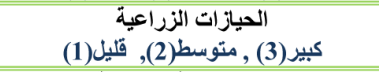 & \\
\hline & 108 & 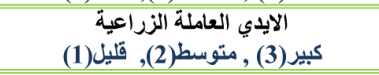 & \\
\hline & 106 & كبير(3) , متتوسطية الزراعية) قليل (1) & \\
\hline & 105 & كبير(3) , متوسطية (2), قليليل (1) & \\
\hline & 176 & 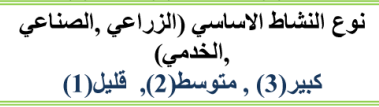 & \\
\hline & 304 & كبير(3) , متوسطط(2), قليليل(1) & \\
\hline & \multirow{2}{*}{48} & الصناعات & \\
\hline & & كبير(3) , متوسط(2), قليل(1) & \\
\hline & 160 & كبير(3) , متئوسطية الآثرية و والدينية & \\
\hline & 1712 & المجموع & \\
\hline الترجيحي & قالوزنة & المؤشرات & الرئيسية \\
\hline \multirow{5}{*}{2109} & 216 & كبير(3) , متّوسط السكان ق قليل(1) & \multirow{5}{*}{ السكان } \\
\hline & 141 & 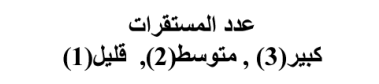 & \\
\hline & 161 & كبير(3) , متوسطانية الاجمالية (2) & \\
\hline & 185 & 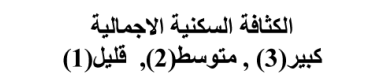 & \\
\hline & 703 & اللجموع & \\
\hline \multirow{8}{*}{2628} & 538 & 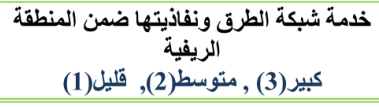 & \multirow{4}{*}{ الخمات } \\
\hline & 253 & كبير(3) , متوسطر(2), قليل(1) & \\
\hline & 265 & كبير(3) , متوسطرباء), قليل(1) & \\
\hline & 61 & 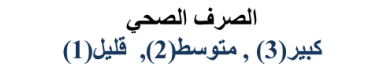 & \\
\hline & \multirow{2}{*}{159} & التعليم & \\
\hline & & كبير(3) , متوسط(2), قليل(1) & \\
\hline & 38 & كبير(3) , متوسطرة), قليل(1) & \\
\hline & 1314 & المجموع & \\
\hline
\end{tabular}




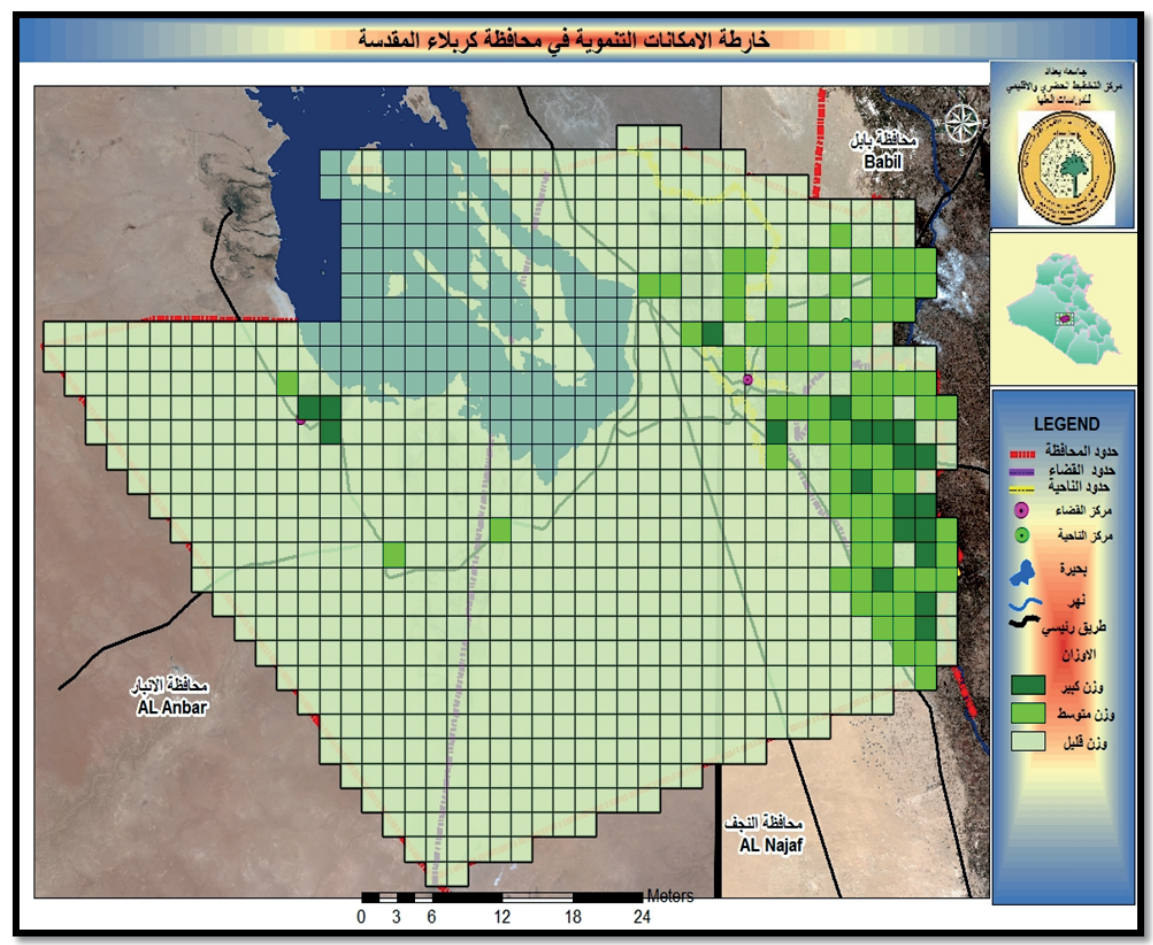

خارطة س: الامكانات التنموية في محافظة كربلاء المقدسة. المصدر: الباحثة

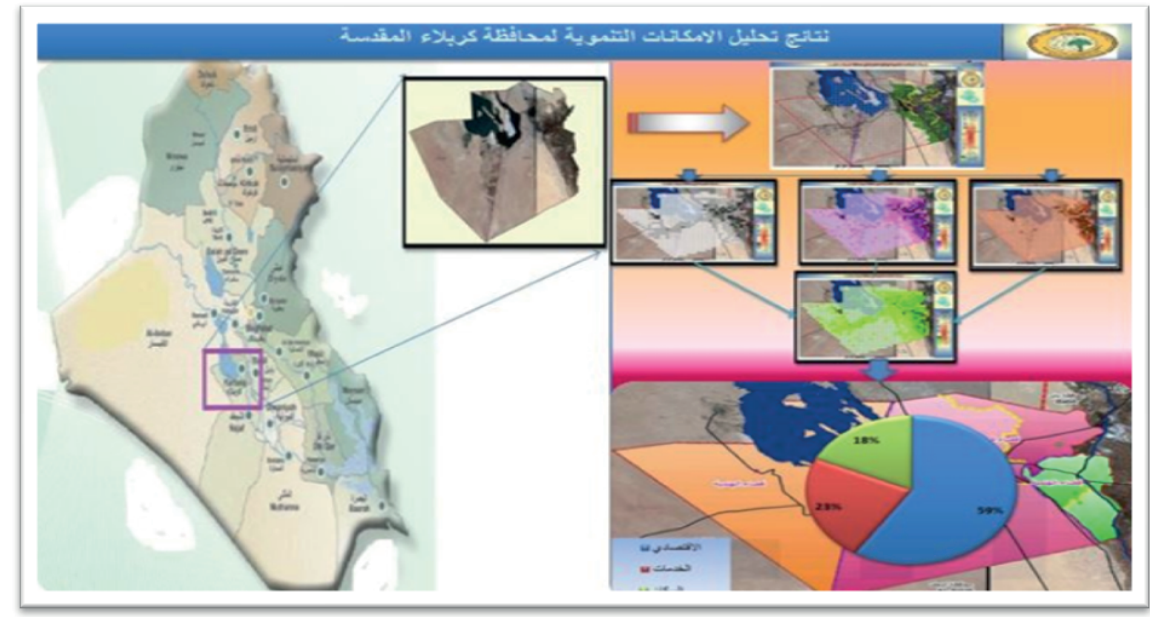

شكل ا: نتائج تحليل الامكانات التنموية لمحافظة كربلاء المقدسة.

ومن خلال مصفوفة التفاعل المكاني بين القطاعات والعوامل المؤثرة لاختيار البدائل نستطيع التوصل

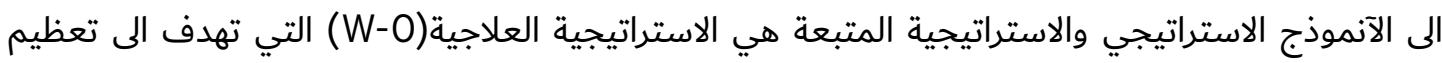
استغلال الفرص وتقليل أستخدام نقاط الضعف بالاعتماد على نقاط القوة للمرحلة الحالية واللاحقة وضمن الامكانات التنموية المتوسطة. وكما موضح ذلك في أنموذج التحليل المزدوج للتفاعل المكاني التنموي. 


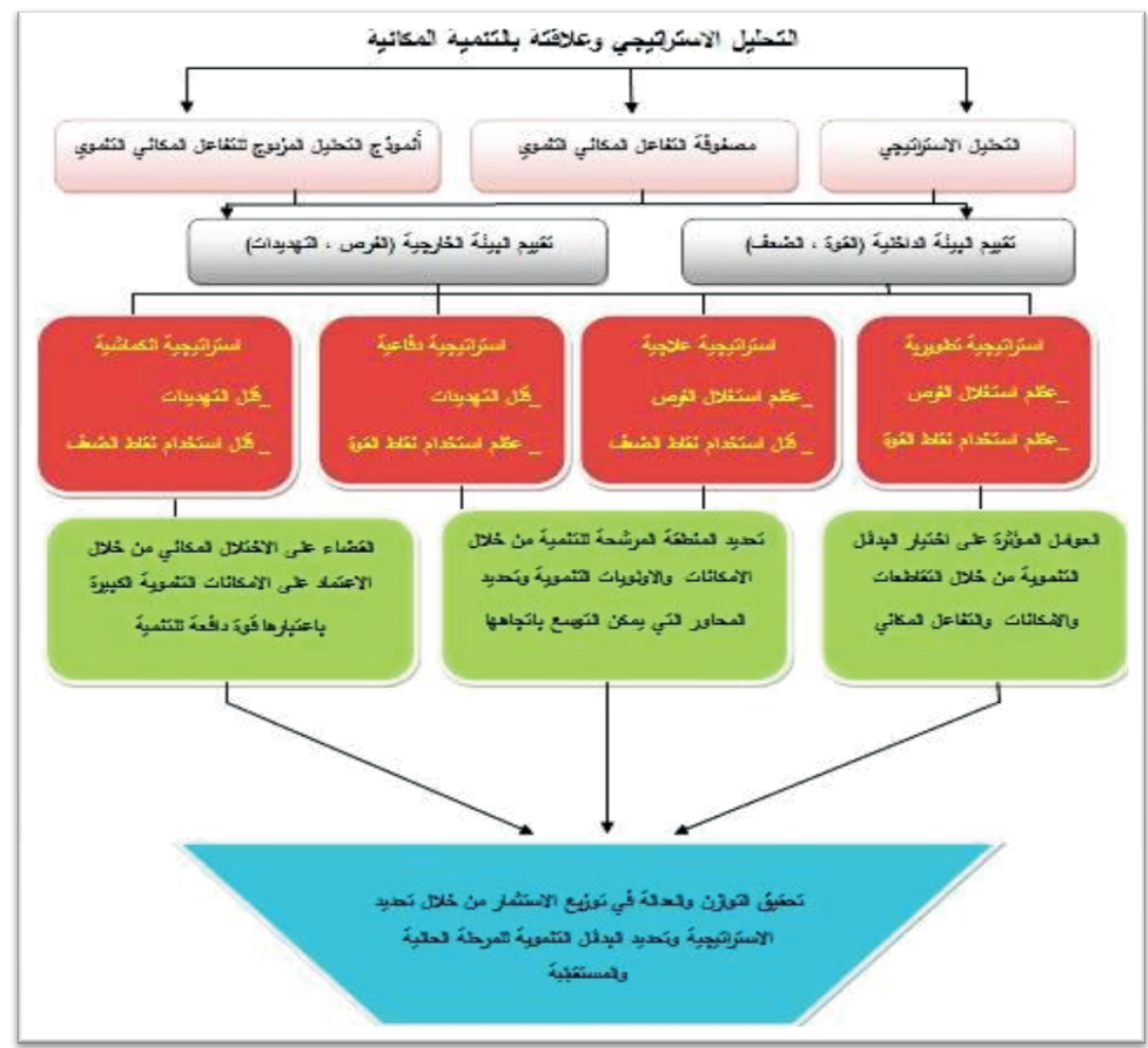

مخطط سّ: الاطار العام للتحليل الاستراتيجي واتخاذ القرار. المصدر: الباحثة

\section{ع. تحديد البدائل التنموية:}

البديل الاول: هو المربعات التنموية ذات الامكانات المتوسطة التي توضحه الخارطة (س) وتتصف بتنوع الامكانات

البديل الثاني: يتم البدء بالتنمية فيه من خلال الوفورات الداخلية والخارجية التي ستوفرها المرحلة الاولى من التنمية.

إن التوازن الذي تفرضه طبيعة العلاقات التفاعلية ما بين القطاعات والعوامل المؤثرة لاختيار البدائل والتفاعل مع ألإنموذج التنموي ساعد في تحديد الاستراتيجية التنموية التي تعزز مرونة اتخاذ القرارات الاستراتيجية الفاعلة وتحقيق التنمية المكانية.

ا. أهمية النمذجة المكانية في حساب الامكانات التنموية الريفية في محافظة كربلاء اعتماداً على تقنيات ال (GIS) لدعم القرار الاستراتيجي وبناء قاعدة بيانات مكانية.

r. القرارات التخطيطية المستندة الى الأساليب التخطيطية الحديثة تكون فعالة في تحقيق التنمية المكانية الريفية من خلال معالجة نقاط الضعف واستغلال الفرص وتقليل التباين والفروقات في الخصائص الوظيفية للمحافظة. 
".. الدمج بين الاساليب التحليلية وأسلوب التخطيط الاستراتيجي الحديث بالاستفادة من اسلوب الامكانات

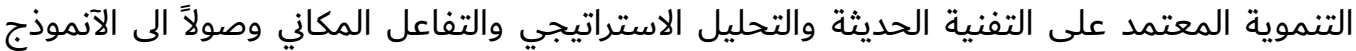
المزدوج للتفاعل المكاني وتحديد البدائل واتخاذ القرار التخطيطي التنموي الافضل من خلال تبني الاستراتيجية العلاجية لتحقيق الرؤية المستقبلية للتنمية الريفية.

جدول 7: يبين مصفوفة التفاعلات بين النشاطات والقطاعات الاقتصادية.

\begin{tabular}{|c|c|c|c|c|}
\hline السياحة & الصناعة & الزراعة & المستقرات الريفب. & ل التنموي \\
\hline 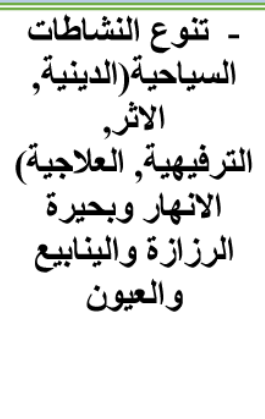 & 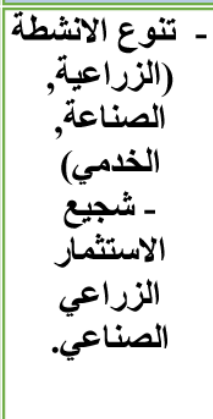 & 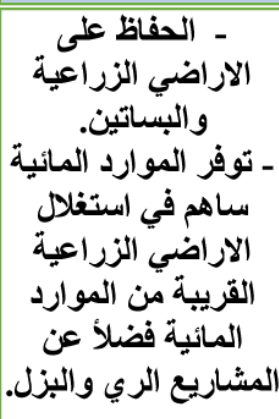 & | وتياستات الانتشيعار & القطاع الاقتصادي \\
\hline 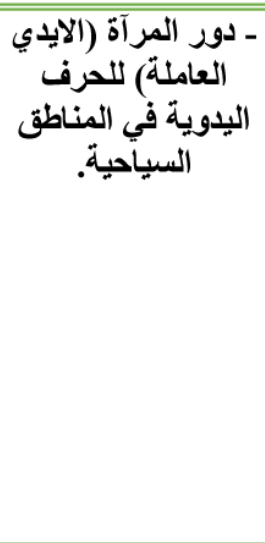 & و الصنا الصناعات & 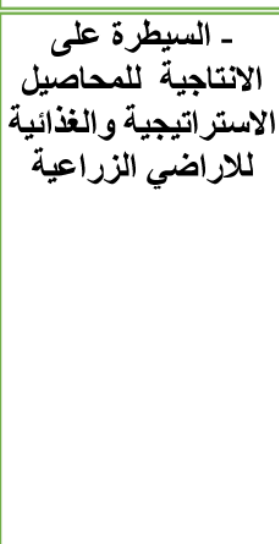 & 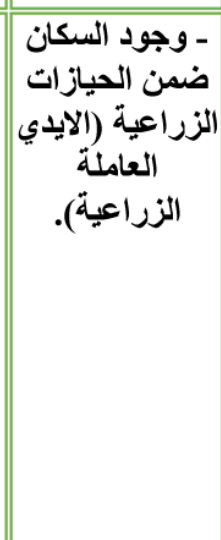 & قالاسكان \\
\hline 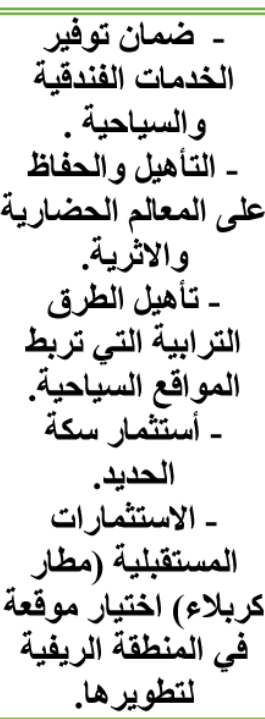 & 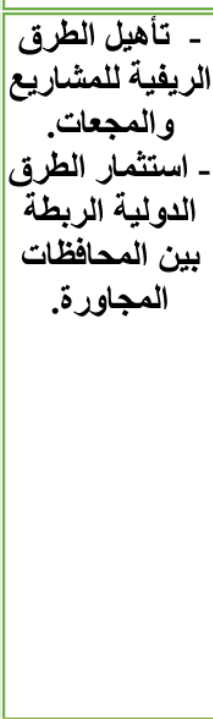 & 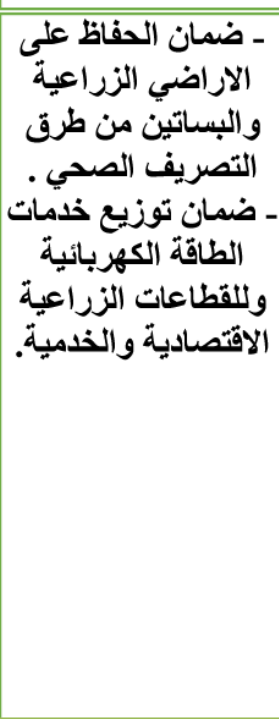 & 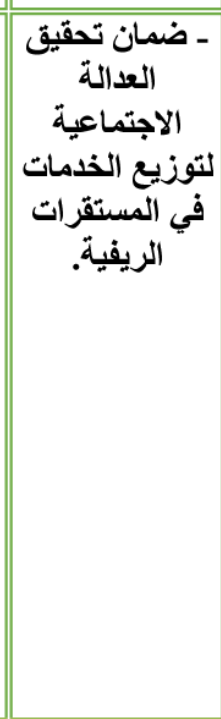 & قالخاع \\
\hline
\end{tabular}




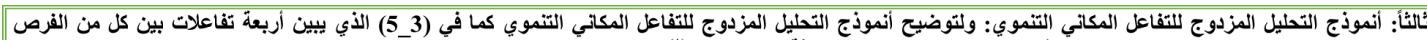
والتهديدات ،وبين كل من نقاط الضعف والقوة وهذه التفأعلات هي بموجب مصفوفة التحلئليل الآتيل"):

\begin{tabular}{|c|c|c|}
\hline \multicolumn{2}{|l|}{ الضعف } & القوة \\
\hline \multicolumn{2}{|c|}{ 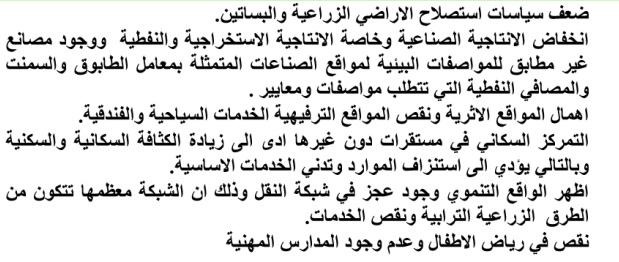 } & 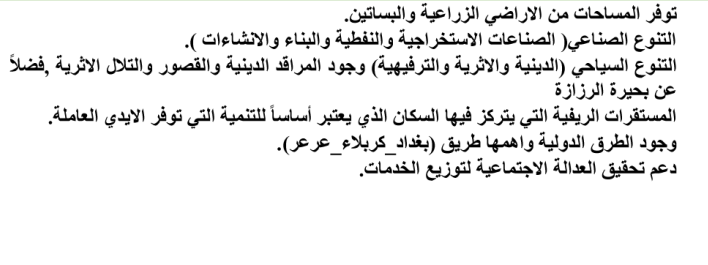 \\
\hline ( W-O)( استر اتيجية علاجية & |متر اتيجية تطويرية & الفرص الفر \\
\hline 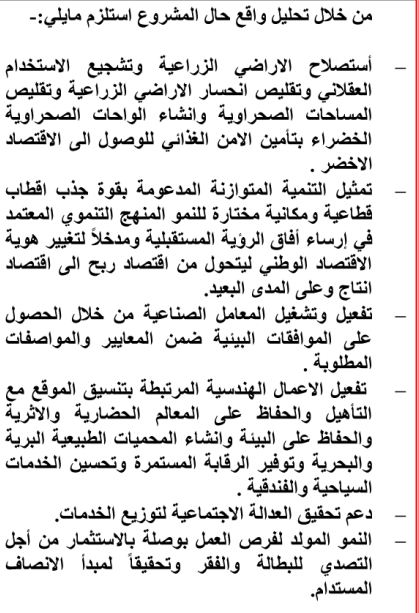 & 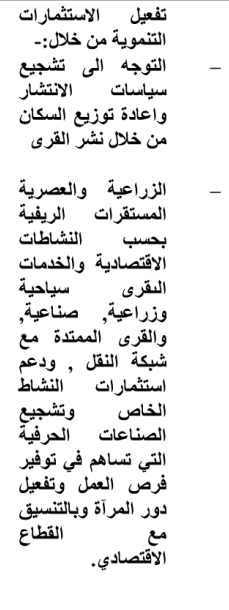 & 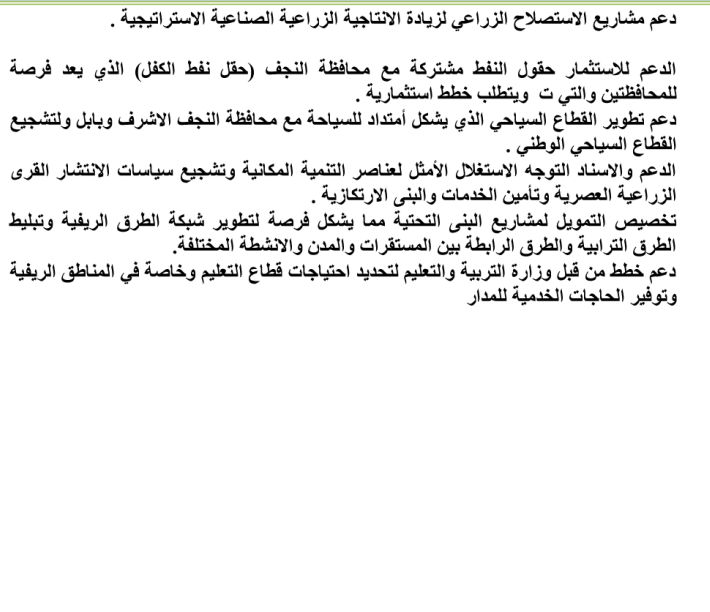 \\
\hline تتظلب ما يسي:- اتيجية انكماشبة (W-T) & التستراتيجية دفاعية (S-T) & التهديدات \\
\hline 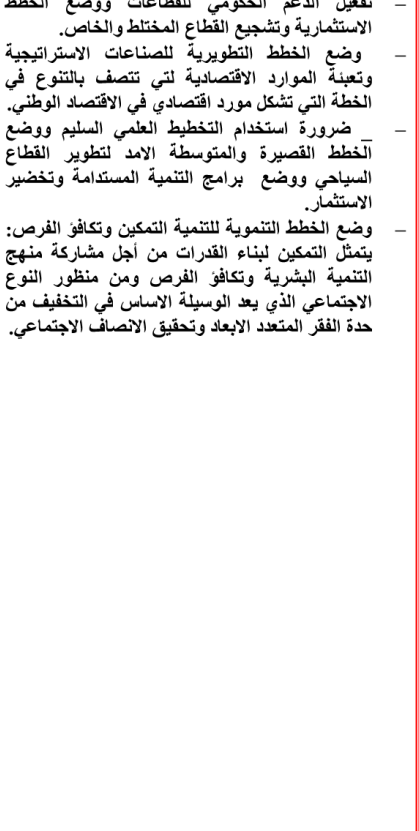 & 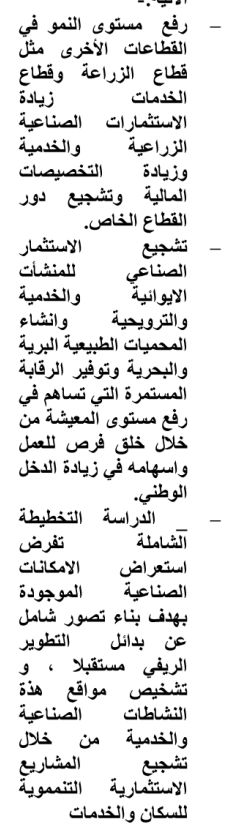 & 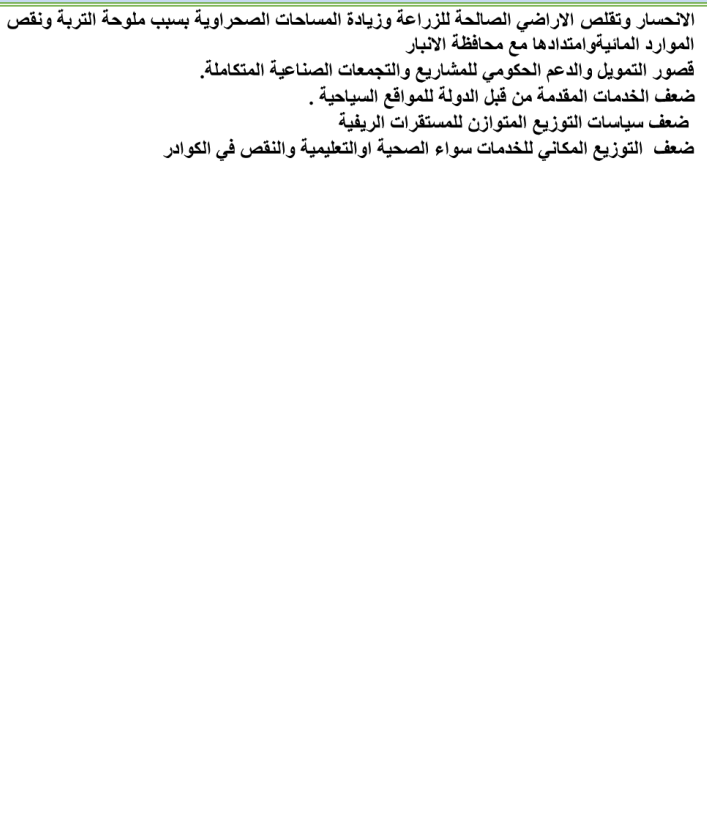 \\
\hline
\end{tabular}


جدول ^: (*) الباحثة بالأعتماد على مصدر (7).

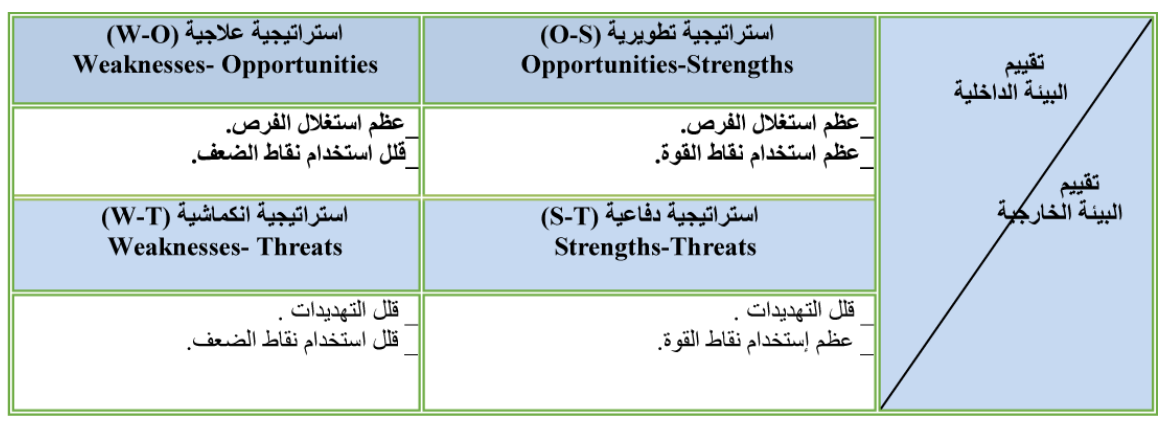

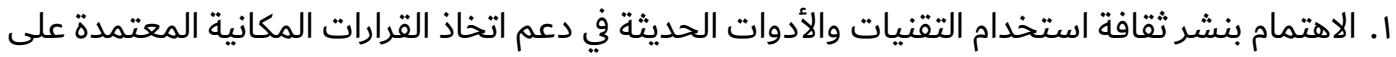

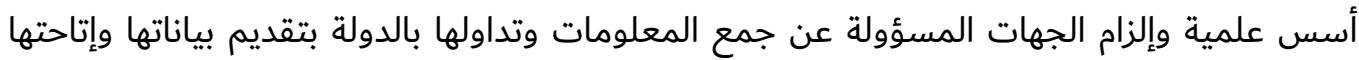
بصورة رقمية ومكانية على شبكة الانترنت بشفافية حتى يسهل على الباحثين والمخططين إدماج هذه البيانات بسرعة في عمليات التحليل والنمذجة.

r. تبني السياسات الاستثمارية في القطاعات التي لها الأولوية بوصفها نشاطات اساسية ضمن الاستراتيجيات وخاصة القطاع الاقتصادي الذي يشمل كل من الزراعة، والصنات الاعة التاعة، والسياحة التي حددتها التوجهات التنموية التخطيطية. س. تعميم منهجية وثقافة التخطيط التنموي الاستراتيجي وثقافته وربط التخطيط الاستراتيجي بالمخططات

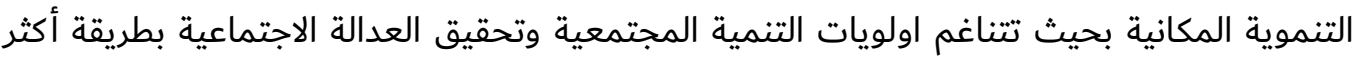
شمولية ودقة, وانشاء قاعدة بيانات وطنية شاملة.

[1] سعيد, سهيلة عبد الله, "الأساليب الكمية وبحوث العمليات " دار الحامد للنشر والتوزيع, عمان V. • م. [r] شرف, محمد إبراهيم محمد,"التحليل المكاني باستخدام نظم المعلومات الجغرافية ", دار المعرفة

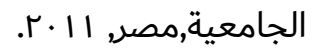

[ץ] الفضل, مؤيد عبد الحسين, "نظريات اتخاذ القرارات منهج كمي", دار المناهج للنشر والتوزيع عمان

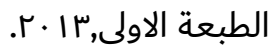
[ع] الموسوي, منعم زمزير, "مدخل علمي لإتخاذ القرارات", دار وائل للنشر عمان, 9. . بـ.

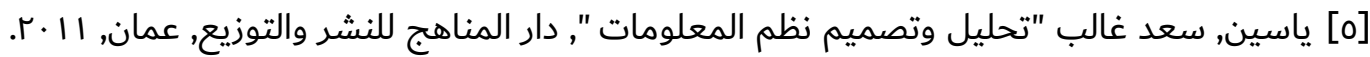
[7] علي، آمنة حسين صبري،"إستراتيجية التنمية المحلية في العراق خيارات في تنمية الموارد البشرية وبناء

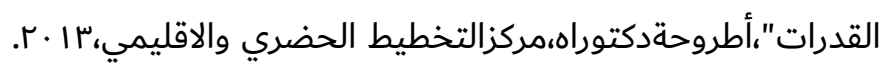

[7] Wheelen, Tomas \& Hunger, David, "Strategic Management \& Business Policy", $7^{\text {th }}$ ed., Prentic- Hall, New Jersey, 2000. 
[^] وزارة البلديات والاشغال العامة المديرية العامة للتخطيط العمراني,"الخطة الهيكلية لمحافظة كربلاء

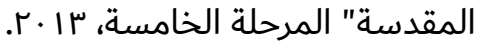

\section{References}

[1] Saeed, Suhaila Abdullah, "Quantitative Methods and Operations Research" Dar Al-Hamed Publishing and Distribution, Amman 2007.

[2] Sharaf, Mohamed Ibrahim Mohamed, "Spatial Analysis Using Geographical Information Systems", Dar Al-Maarefah University, Egypt, 2011.

[3] Al-Fadl, Mo'ied Abdul-Hussain, "Theories of Decision-Making a Quantitative Approach", Dar Al-Manahig for Publishing and Distribution Amman, First Edition, 2013.

[4] Al-Mousawi, Menem Zamzair, "A Scientific Approach to Decision Making", Dar Wael Publishing Amman, 2009.

[5] Yasin, Saad Ghaleb, "Analysis and Design of Information Systems", Dar AlMaaishah Publishing and Distribution, Amman, 2011.

[6] Ali, Amna Hussain Sabree "Local Development Strategy in Iraq Options in Human Resource Development and Capacity Building", PhD thesis, Urban and Regional Planning Center, 2013.

[7] Wheelen, Tomas \& Hunger, David, "Strategic Management \& Business Policy", 7th ed., Prentic- Hall, New Jersey, 2000.

[8] Ministry of Municipalities and Public Works General Directorate of Urban Planning, "Structural Plan of Karbala Holy Province" Phase V, 2013 